\title{
Role of the Duodenum in the Pathogenesis of Functional Dyspepsia: A Paradigm Shift
}

\author{
Hye-kyung Jung ${ }^{1}$ and Nicholas J Talley ${ }^{2 *}$ \\ ${ }^{I}$ Department of Internal Medicine, College of Medicine, Ewha Womans University, Seoul, Korea; and ${ }^{2}$ University of Newcastle and Hunter \\ Medical Research Institute, Newcastle, NSW, Australia
}

Functional dyspepsia (FD) is a common disorder characterized by chronic epigastric pain or burning, or bothersome postprandial fullness or early satiation, without a definitive organic cause. The pathogenesis of FD is likely heterogeneous. Classically, motor disorders, visceral hypersensitivity, and brain-gut interactions have been implicated in the pathophysiology of FD, but recently an important role for chronic low-grade inflammation and infection in FD has been reported and confirmed. Duodenal low-grade inflammation is frequently observed in FD in those with and without documented previous gastroenteritis. Duodenal eosinophils and in some cases mast cells may together or separately play a key role, and immune activation (eg, circulating homing small intestinal $T$ cells) has been observed in FD. Low-grade intestinal inflammation in patients with FD may provoke impairment in motor-sensory abnormalities along the gastrointestinal neural axis. Among FD patients, the risk of developing dyspeptic symptoms after a bout of gastroenteritis is $2.54(95 \% \mathrm{Cl}, 1.76-3.65)$ at more than 6 months after acute gastroenteritis. Gut host and microbial interactions are likely important, and emerging data demonstrate both quantitative and qualitative changes of duodenal mucosal and fecal microbiota in FD. Food antigens (eg, wheat proteins) may also play a role in inducing duodenal inflammation and dyspepsia. While causation is not established, the hypothesis that FD is a disorder of microscopic small intestinal inflammation in a major subset is gaining acceptance, opening the possibility of novel treatment approaches that may be able to alter the natural history of the disorder.

(J Neurogastroenterol Motil 2018;24:345-354)

Key Words

Duodenum; Dyspepsia; Eosinophils; Inflammation

\section{Introduction}

Functional dyspepsia (FD) is a chronic symptom complex characterized by epigastric pain or burning, postprandial fullness, or early satiation. ${ }^{1}$ The symptoms are thought to arise from the gastroduodenal region without any organic, metabolic, or systemic disease that is likely to explain the symptoms. ${ }^{2} \mathrm{FD}$ is a common but heterogeneous condition. Gastro-duodenal motor dysfunction, including delayed gastric emptying or hypo-motility, dysfunction of gastric accommodation, and altered intestinal hypersensitivity have been the focus of attention until recently. ${ }^{3-7}$ The prevalence of motor dysfunction is about $20-30 \%$ in patients with FD including occasionally rapid gastric emptying. ${ }^{3,4}$ While slow gastric emptying has been associated with FD symptoms in some studies, in particular post-prandial fullness and severe vomiting in $\mathrm{FD},{ }^{5}$ large scale, multi-center studies have failed to demonstrate any link between gastric emptying and specific symptoms. ${ }^{6,7}$

Received: March 26, 2018 Revised: None Accepted: May 4, 2018

(.) This is an Open Access article distributed under the terms of the Creative Commons Attribution Non-Commercial License (http://creativecommons. org/licenses/by-nc/4.0) which permits unrestricted non-commercial use, distribution, and reproduction in any medium, provided the original work is properly cited.

*Correspondence: Nicholas J Talley, MD, PhD

Hunter Medical Research Institute, University of Newcastle, Kookaburra Circuit, Newcastle, NSW 2258, Australia

Tel: +61-249215855, Fax: +61-240420034, E-mail: nicholas.talley@newcastle.edu.au 
The duodenum serves to regulate acid secretion from the stomach and the nutrient absorption in the small intestine via local signaling pathways, and connects with the central nerve system, via neuronal and endocrine mediators. ${ }^{8}$ Duodenal acidification may provoke epigastric pain and aggravate dyspeptic symptoms through the induction of hypersensitivity to gastric distension in healthy subjects. ${ }^{9}$ Intra-duodenal lipid, not glucose, may be responsible for symptom generation in FD through the induction of a duodenogastric reflex resulting in gastric relaxation, inhibition of antral motility, and increased sensitivity of the proximal stomach to distension, or an abnormal response to cholecystokinin in patients with $\mathrm{FD} .{ }^{10}$

In $\mathrm{FD}$, there are traditionally no structural or biochemical abnormalities found that explain chronic symptoms, however, recent research is providing evidence of structural upper gut alterations in certain subsets. In particular, subtle inflammatory and molecular changes in the duodenum may play an important role in the pathophysiology of FD. In this review, we discuss the proposed link between chronic low-grade inflammation and the pathogenesis of FD, potential treatment implications, and future perspectives.

\section{Quantitative Assessment of Low-grade Inflammation in Functional Dyspepsia}

Low-grade inflammation in patients with functional gastrointestinal (GI) disorders may provoke localized impairment in motor-sensory abnormalities, the GI neural axis, and neuroimmuno-dysregulation. Duodenal micro-inflammation is observed in $\mathrm{FD}$, and has been associated with dyspeptic symptoms, such as postprandial symptoms and epigastric pain, in adults and pediatric populations. ${ }^{1-13}$ The landmark study was conducted using a population based endoscopic study approach allowing for the inclusion of a representative community control group without $\mathrm{FD} .{ }^{11}$

Eosinophils and mast cells may have a potential key role, through a variety of immune responses. ${ }^{12}$ Recent studies on lowgrade inflammation in patients with $\mathrm{FD}$ are expressed using quantitative assessments (Fig. 1). A meta-analysis of 37 studies evaluating peripheral and mucosal immune cytokines and inflammatory cells was performed. ${ }^{14}$ Gastric mast cells were increased in patients with FD compared to controls, and in a subgroup analysis of 3 studies evaluating FD patients without Helicobacter pylori infection, mast cell counts remained elevated in FD compared to controls. ${ }^{15-19}$ However, a number of studies failed to find an increase including a population-based case control endoscopic study. ${ }^{12}$ A significant increase of eosinophils was also noted in the stomach of FD patients compared to controls. ${ }^{11,15,18-22}$ Duodenal intra-epithelial lymphocytes and neutrophils were not different among individuals between FD and controls, ${ }^{12,22-25}$ and inflammatory cytokines in the stomach of FD patients, such as IL-1 $\beta$, IL-6, IL-8, and IL-10, were not different but with study inconsistency. ${ }^{17,18,20,23}$ The enterochromaffin cells (ECs) in the stomach were similar between 2 groups and serotonin contents, serotonin contents, TPH-1 mRNA, a rate limiting enzyme of 5-hydroxytryptamine synthesis in ECs, SER mRNA expression also were not different among individuals with $\mathrm{FD}$ and controls. ${ }^{20}$ In another study, the number of endocrine cells was significantly lower in FD patients versus controls, whereas there was no significant difference in 5-hydroxytryptamine content. ${ }^{26}$
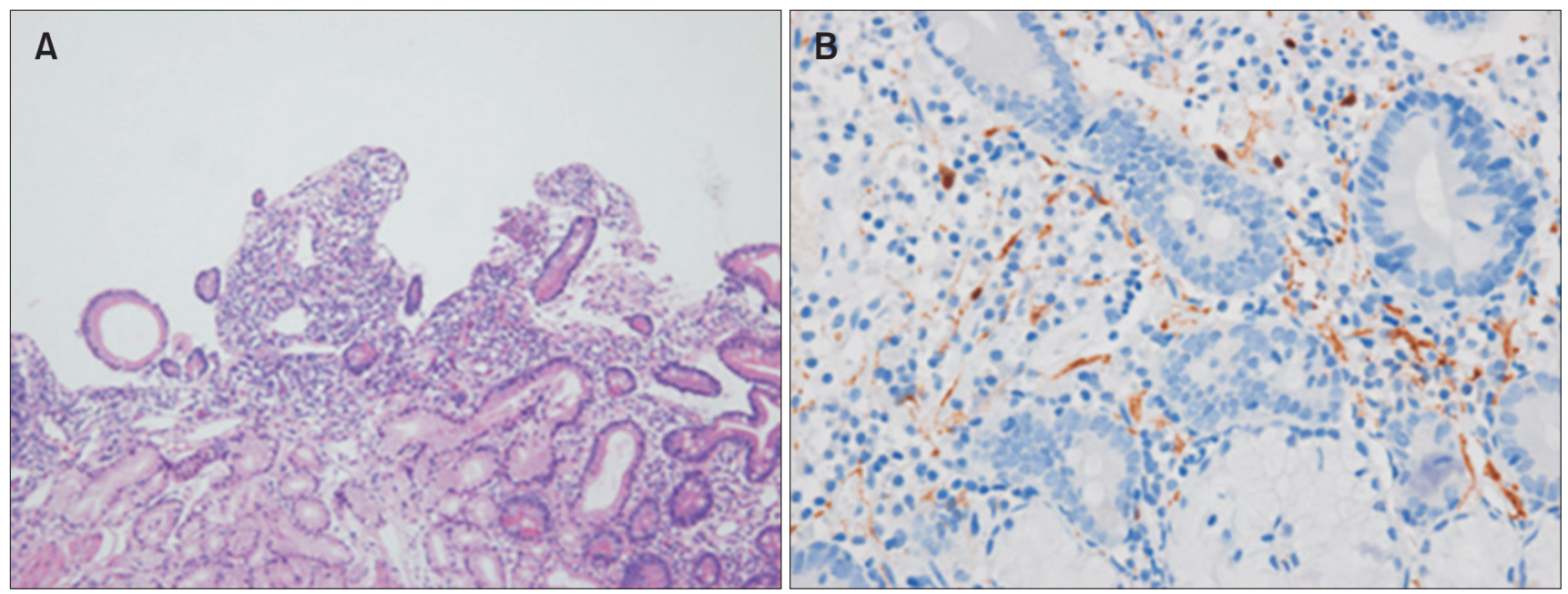

Figure 1. Microscopic findings of duodenal eosinophil infiltration in functional dyspepsia. (A) H\&E (×100). (B) Immunohistochemical stain with major basic protein for detection of activated eosinophils in duodenum. 
In an adult population based endoscopic study, eosinophils were specifically increased in the duodenum of FD community subjects, but mast cells were also significantly increased in FD subjects with overlapping IBS and $\mathrm{FD} .{ }^{12}$ In a meta-analysis, increased duodenal eosinophils infiltration was noted in patients with $\mathrm{FD}$ compared to controls, despite significant heterogeneity and possible publication bias. ${ }^{14}$ Two studies showed increased eosinophils in postprandial distress syndrome (PDS), ${ }^{11,23}$ not in epigastric pain syndrome (EPS), however, a subgroup meta-analysis demonstrated higher duodenal eosinophil counts in both EPS and PDS. Of the 10 studies that evaluated mast cell infiltration, 5 studies reported increased duodenal mast cells and the pooled results showed significantly higher mast cell counts in the duodenum. ${ }^{14}$ It is unclear if the increase in duodenal mast cells is restricted to those with FD and IBS overlap (one third of FD cases), ${ }^{12}$ as increased mast cells have also been observed in the terminal ileum and jejunum in IBS. ${ }^{27,28}$

\section{Activation of Low-grade Inflammation Related With Overt Infection}

Eosinophils are detected normally at low levels in the GI tract from the stomach to the small and large intestine. Unlike intraepithelial lymphocytes and mast cells, eosinophils are not normally present in Peyer's patches or intraepithelial locations. Mature mast cells are ready for optimal interaction with the local environment and comprise $1-5 \%$ of mononuclear cells in the lamina propria and the submucosa of the gut. ${ }^{29} \mathrm{~A}$ reference range for significant increased eosinophils and mast cell counts is still lacking because of the standardization on the methodology used to count these cells, differences in patients and control selection, inter-individual variability, geographic variation, and the relatively small numbers for individual studies.

The eosinophil has pleomorphic effects: (1) eosinophils release cytotoxic granules, eosinophil peroxidase, major basic protein, eosinophil cationic protein, and eosinophil-derived neurotoxin; (2) eosinophils release a variety of cytokines and neuro-mediators; (3) eosinophils release lipid mediators, such as leukotrienes or platelet activating factor; and (4) eosinophils induce the expression of MHC class II and co-stimulatory (eg, B7) molecules by presenting antigen to T-cells leading to immune activation. ${ }^{30}$

Mast cells induce bone marrow-derived eosinophils to migrate into the mucosa and in turn, eosinophils can activate mast cells via cytokines or mediators. ${ }^{30}$ Eosinophil-derived major basic proteins can induce vagal M2 receptor dysfunction. ${ }^{31}$ Also, eosinophils activate mast cells which release leukotrienes, a potent stimulator of smooth muscle. ${ }^{30}$ Mast cell activation provokes the spontaneous or stimulated release of mediators, most commonly tryptase and histamine and less often carboxypeptidase A2, heparin, hexosaminidase, chromogranin A, leukotriene E4, and prostaglandin D2. ${ }^{29}$ Recent studies suggest that proton pump inhibitors (PPIs) directly inhibit IL-4 stimulated eotaxin-3 expression, an eosinophil chemo-attractant, and block STAT6 binding to the promoter in patients with eosinophilic diseases. ${ }^{32,33}$ These findings suggest that PPIs may have a therapeutic value in a subset of patients with FD through a direct anti-inflammatory action, and in randomized controlled trials PPIs are superior to placebo in FD particularly PDS. ${ }^{34}$

$H$. pylori infection clearly provokes chronic mucosal inflammation in the stomach and duodenum, which in turn, might lead to gastroduodenal motor and sensory dysfunction, and also has been linked with dyspeptic symptoms. In subjects with $H$. pylori infection, the increase in eosinophils was not significantly correlated with the degree of gastric or duodenal mucosal inflammation or the accompaniment of allergy, but the eosinophil count in the esophagus and gastric mucosa was significantly higher compared to a $H$. pylori negative group. ${ }^{35} \mathrm{~A}$ recent meta-analysis showed that mast cells and eosinophils were increased in patients with FD compared to controls, however, in a subgroup analysis of 3 studies evaluating its association with $H$. pylori infection, gastric mast cells were still increased, but gastric eosinophils were not increased in FD subjects without $H$. pylori infection. ${ }^{18,19,22}$

$H$. pylori is a common and worldwide infection, with a prevalence ranging from $18.9 \%$ to $87.7 \%{ }^{36}$ which is regionally diverse. Furthermore, the presence of $H$. pylori is not associated with any specific symptom profile. ${ }^{37}$ A recent meta-analysis reported a significant improvement in dyspeptic symptoms in the $H$. pylori treatment group (40.6\%) versus controls (34.0\%). The number needed to treat for $H$. pylori eradication to provide dyspeptic symptom improvement was 15 , a modest effect. ${ }^{38}$ Although the magnitude of the relevance of $H$. pylori infection in $\mathrm{FD}$ has been a contentious issue, it does seem that its eradication provide symptom relief in as small subset.

Among a subset of FD patients, dyspeptic symptoms may arise after a bout of gastroenteritis, so called post-infectious FD. Salmonella, Escheria coli, Giardia lamblia, Campylobacter jejuni, and norovirus may lead to the development of new onset chronic dyspeptic symptoms after an acute bout of gastroenteritis that resolves. ${ }^{39}$ A meta-analysis revealed that the prevalence of post-infectious FD was around $10 \%$ in the adult population, and the summary odd ratio for the development of post-infectious $\mathrm{FD}$ was $2.54(95 \% \mathrm{CI}$, 1.76-3.65) at more than 6 months after acute gastroenteritis. ${ }^{40}$ Post- 
infectious FD is presumed to induce a persistent inflammatory state due to the occurrence of inefficient down-regulation of the immune response to the initial infectious agent. In patients with postinfectious-FD, duodenal biopsy revealed persisting focal CD8+ T-cell aggregates, and decreased numbers of CD $4+\mathrm{T}$ cells. ${ }^{41}$ Another study from Japan provide additional evidence of immune dysfunction by showing microscopic duodenitis with increased eosinophils and CD68+ and chemokine receptor 2 (CCR2)+ macrophages. ${ }^{42}$ In a study comparing $37 \mathrm{FD}$ patients with a history of acute gastroenteritis 6 to 12 months ago and non-specific FD patients, the number of ECs and mast cell were increased in the gastric antrum. ${ }^{43}$ Electron microscopy revealed activating mast cells and ECs at a distance of $<5 \mu \mathrm{M}$ of nerve fibers were significantly greater in post-infectious FD in the antrum versus nonspecific FD or controls. ${ }^{43}$

\section{Gastric Acid}

Increased viscero-perception is an important etiologic factor in FD and acid may play a role. Although meta-analysis revealed that PPIs and histamine $\mathrm{H}_{2}$ receptor antagonists are efficacious therapies for treating FD, low-dose PPIs have similar efficacy as standard-dose PPIs. ${ }^{34}$ Furthermore, gastric acid secretion is within the normal range in these patients. ${ }^{44}$ Duodenal acidification induces gastric relaxation by exerting an inhibitory effect on the stomach slowing gastric emptying. ${ }^{45,46}$ Intraduodenal acid, but not saline, increased upper GI symptoms and an experimental hyper-acidic state in the proximal duodenum decreased duodenal contractile velocity in patients with $\mathrm{FD}$, but not in healthy volunteers. ${ }^{47,48}$

\section{Duodenal Sensory-neural Aberration Related With Inflammation}

Low-grade inflammation in FD, most notably eosinophils and mast cells, is likely to alter neural structure and function. ${ }^{49}$ In IBS, mast cells in close proximity to nerves in the colonic mucosa significantly correlated with the frequency and severity of abdominal pain or discomfort. ${ }^{50}$ The co-labeling technique of mast cells and nerves in fixed human specimens revealed altered cell density and reactivity, however, application of advanced imaging techniques based on the use of dyes that detect changes in membrane potential or intracellular calcium have enabled the detection of nerve activation in submucosal or myenteric plexus layers of human tissues. ${ }^{51} \mathrm{In}$ patients with IBS, increased mast cells in the colonic mucosa were localized close to the nerve fibers, with a marked increase in the fir- ing rate of visceral sensory nerves and enhanced $\mathrm{Ca}_{2}{ }^{+}$mobilization in the vast majority of capsacin-sensitive dorsal root ganglion neurons following exposure to IBS mucosal supernatants. ${ }^{49}$ Therefore, mast cells in the mucosa of patients with IBS can release mediators that excite afferent neurons and may cause visceral hypersensitivity.

There are a few studies on the potential role of the eosinophilmast cell axis in altering enteric nervous system function in FD patients. In pediatric patients with FD who also had atopy, increased mast cells were closely associated with mucosal nerve fibers and released tryptase co-localized with proteinase-activated receptors on mucosal nerve fibers. ${ }^{52}$ Cirillo et al ${ }^{53}$ demonstrated impaired neuronal function in the submucous plexus of FD patients, as shown by decreased calcium responses to depolarization and electrical stimulation. Further, the neuronal impairment significantly correlated with eosinophil and mast cell infiltration in the submucosal layer of FD patients. They hypothesized that, through mediator release and recruitment of mast cells and eosinophils, neuronal muscle cell functioning is altered. There was a significant negative correlation between nerve activity and immune cell numbers. ${ }^{52,53}$

Gut-trophic $\mathrm{T}$ cells that express high levels of $\alpha 4$-integrin (CD49d) and $\beta 7$-integrin and CCR9 tend to migrate to the lamina propria of the small intestine. ${ }^{54}$ Circulating $\mathrm{CD}^{+}{ }^{+} \mathrm{CR} 9^{+} \mathrm{T}$ cells are increased in the peripheral blood of patients with small bowel celiac disease and Crohn's disease. ${ }^{55} \mathrm{CD} 4+\mathrm{T}$ lymphocytes coexpressing the gut homing marker CD49d, $\beta 7$-integrin, and CCR9 were increased in $H$. pylori-negative FD patients, which demonstrated an association of systemic cellular immune activation with symptom manifestation in $\mathrm{FD} .^{56}$

Psychological factors, as manifested by anxiety or depression, may contribute to the immune activation or be in some cases driven by it. ${ }^{57}$ Corticotrophin-releasing hormone $(\mathrm{CRH})$ is released by stress by activation of the hypothalamus, and also produced by peripheral inflammatory cells. ${ }^{58}$ In patients with IBS, anxiety was related to increased infiltration of rectal mast cells, and anxiety, depression, and somatization yielded statistically significant relationships with gastric mast cell density in pediatric FD patients. ${ }^{59,60}$ Neuro-immune interactions have been implicated in IBS, ${ }^{61}$ which can be precipitated by physical or psychological stress. ${ }^{62,63}$ Acute stress evoked by immobilization leads to colonic responses via $\mathrm{CRH} .{ }^{64} \mathrm{CRH}$ can induce intestinal mast cell degranulation directly leading to increased vascular permeability. ${ }^{58}$

Taken together, the data suggest that low-grade inflammation may activate the enteric nervous system and interact with the central nervous system. Higher pre-existing psychological problems also may result in autonomic nervous system imbalance, further impair- 
ing sensory-motor dysfunction.

\section{Interaction Between Low-grade Inflammation and Barrier Function}

The intestinal barrier is a complicated and effective defense system that limits luminal antigen access while maintaining nutrient and electrolyte absorption. Intestinal permeability is mainly determined by epithelial physicochemical barrier function aided by mucosal immunity and neural activity. ${ }^{65}$ An increase in intestinal permeability has been found in inflammatory bowel disease and IBS, especially diarrhea-predominant IBS or post-infectious IBS $(\mathrm{PI}-\mathrm{IBS})^{66,67}$ and more recently also in FD. ${ }^{23}$

In patients with PI-IBS, intestinal permeability was increased after an outbreak of bacterial gastroenteritis by documentation of an increased lactulose/mannitol ratio in the urine of IBS patients compared to healthy controls. ${ }^{67}$ Increased gut permeability was also noted in non-PI-IBS. ${ }^{68} \mathrm{CDH}-1$, which codes for E-cadherin, a tight junction protein, is linked to PI-IBS, hence the increased permeability may underlie the pathogenesis of PI-IBS. ${ }^{69}$ The apical junctional complex keeps enterocytes tightly sealed and regulates paracellular permeability. The tight junction is constituted by surface-membrane proteins, including occludin, claudins, junctional adhesion molecules and tricellulin, and intracellular proteins, zonula occludins (ZO)-1, 2, 3, which anchor to the actin cytoskeleton. ${ }^{70}$ Adherence junctions are mainly made up of e-cadherin, catenin, and actin filaments. ${ }^{71,72}$ In the colonic mucosa of IBS patients, increased permeability has been linked to the down-regulation of ZO-1 and proteasome-mediated occludin degradation ${ }^{73,74}$ and mast cell activation was associated with down-regulation and redistribution of ZO-1 and occludin in the jejunum. ${ }^{65}$

Vanheel et $\mathrm{al}^{23}$ reported impaired mucosal integrity and abnormal gene expression of occludin, $\beta$-catenin and desmosomal proteins in FD patients compared to controls. Furthermore, there was a significant association between the expression of cell-to-cell adhesion proteins, increased permeability and the low-grade duodenal inflammation. It needs to be determined if the reduced barrier function precedes the activation of local immunity already observed in FD patients and whether this condition drives symptom development.

\section{Microbiome Dysbiosis in Functional Dyspepsia}

Complex dietary components can be converted by the micro-

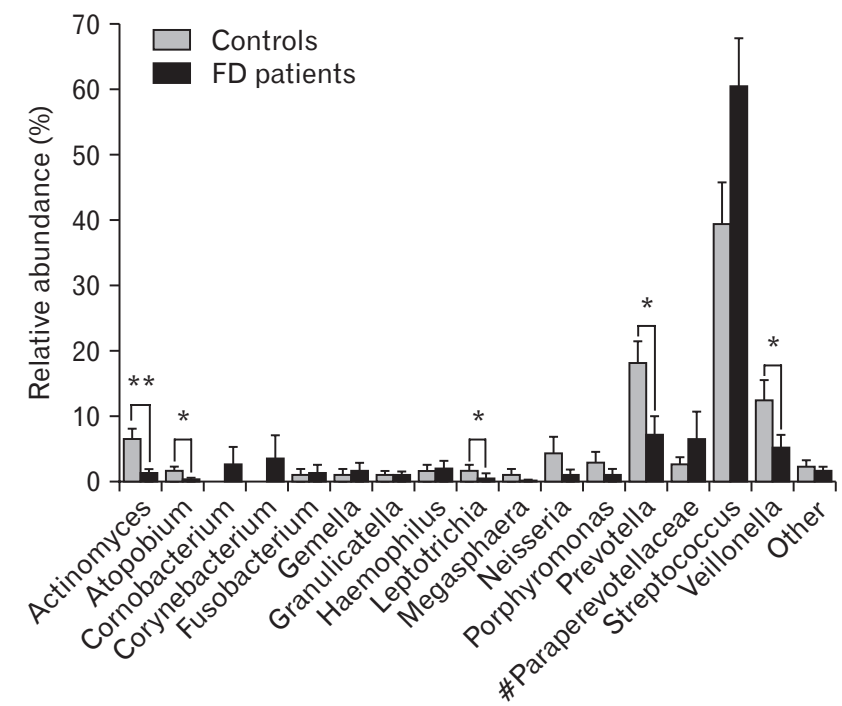

Figure 2. Differences of relative abundance of microbiota in the duodenal mucosa between functional dyspepsia (FD) and controls. The differences were corrected using false discovery rate (FDR) for multiple comparisons. Reprinted from Zhong et $\mathrm{al}^{81}$ with permission. *Mann-whitney- $\mathrm{U} P<0.05, \mathrm{FDR} q=0.02 ;$ ** Mann-whitney- $\mathrm{U} P$ $<0.001$, FDR q $=0.01 ; \#$, family.

biota to produce various metabolites. The fermentation of complex carbohydrates mostly results in the production of short chain fatty acids, such as acetate, propionate, and butyrate. ${ }^{75}$ These metabolites are sensed by the enterocytes and also diffuse across the epithelium, where they can provoke immune activation and be connected with the enteric nervous system. ${ }^{76}$ In patients with IBS, brushings of the duodenal mucosa in patients with IBS showed significantly lower levels of Bifidobacterium catenulatum. ${ }^{77}$

Stress reduces water absorption and increases jejunal secretion in healthy subjects through the parasympathetic nerves and mast cell activation, and the corticotrophin-releasing factor enhances transcellular uptake in the human colon through the CRF-R1 and CRF-R2 receptors on colonic mast cells. ${ }^{78}$ In an IBS rat model, chronic early life stress induced hypercortisolemia, and enhanced intestinal permeability and stress decreased fecal microbial diversity, which was characterized by an increased abundance of grampositive cocci and reduction of fiber degrading, butyrate-producing, and mucus-resistant microbes. ${ }^{79}$ This dysbiosis may affect the susceptibility of people to visceral hypersensitivity through immune activation. Studies on microbiota are rare in dyspepsia patients compared with IBS. Several studies on small intestinal dysbiosis related with PPIs and its impact on the gut have been published. ${ }^{80}$ PPI use is associated with decreased bacterial richness and deviation of oralassociated bacteria in the gut microbiota. ${ }^{80}$ 
Zhong et $\mathrm{al}^{81}$ assessed stool and duodenal mucosal microbiota in patients with FD and controls (Fig. 2). In FD patients, there was an inverse relationship between the relative abundance of Streptococcus and the anaerobic genera, and clear distinction from controls. In an analysis of the gastric fluid microbiota in patients with FD, Bacteroides > Proteobacteria abundance and the absence of Acidobacteria at the phylum was found. ${ }^{82}$

More microbiota studies will be important. Given wide human microbiome heterogeneity and that microbial diversity depends on diet and other environmental exposures, a well standardized methodology and longitudinal studies as well as intervention studies will be needed to determine if duodenal dysbiosis is relevant to the pathogenesis of FD.

\section{Diet and Low-grade Inflammation}

Many patients with FD report meal-related symptoms, such as fullness, bloating, epigastric pain or burning, so it is likely that food and dietary habits can induce and/or exacerbate dyspeptic symptoms. Intra-duodenal infusion of fat, in contrast to glucose, induced dyspeptic symptoms by impaired gastric accommodation in patients with $\mathrm{FD}^{48}$ However, the association between symptoms and motor abnormalities appeared to be relatively weak. The role of dietary factors related directly to food ingestion, including patterns of nutrient intake and potential intolerance to specific foods or macronutrients, might be more important. ${ }^{83} \mathrm{~A}$ recent systematic review showed that dietary fat was associated with dyspepsia onset after a meal challenge, ${ }^{84}$ and the proposed mechanism was by hypersensitivity to GI hormones such as cholecystokinin ${ }^{85}$ or delayed gastric emptying. ${ }^{83}$

Wheat, specifically gluten proteins, may trigger dyspeptic symptoms. Furthermore, a gluten-free diet induced symptomatic improvement in 2 studies, ${ }^{86,87}$ but elimination of dietary wheat also substantially reduces the fermentable oligosaccharides, disaccharides, monosaccharides, and polyols (FODMAP) content. ${ }^{87}$ Nonceliac gluten or wheat sensitivity (NCG/WS) is characterized by upper or lower GI symptoms following the ingestion of gluten- or wheat-containing foods, in the absence of coeliac disease or what allergy. ${ }^{88}$ The underlying mechanism of NCG/WS is unknown, but the innate immune system has been implicated, and there is some possibility of overlap of the condition and FD. Uhde et $\mathrm{al}^{89}$ reported that serum soluble CD14 and lipopolysaccharide-binding protein and fatty acid-binding protein 2, a marker of intestinal cell damage, were significantly elevated in wheat sensitivity, and these results suggest a state of immune activation in conjunction with a compromised intestinal barrier affecting in a subset of NCG/WS.

\section{Treatment Implications}

Duodenal eosinophilia have been documented in children with dyspepsia. In pediatric patients with FD, a randomized controlled trial with monolukast, an eosinophil stabilizing drug, showed that pain and peak eosinophilic infiltration of the duodenum were significantly improved. ${ }^{90}$ Another study was conducted in pediatric dyspeptic patients with duodenal eosinophilia to evaluate the efficacy of a $\mathrm{H} 1 / \mathrm{H} 2$ antagonist. About half of the patients showed a response to histamine $\mathrm{H} 1 / \mathrm{H} 2$ blocker and when oral cromolyn was administered to the non-responders, it appeared effective at $89 \%$. $^{91}$ These studies have stimulated considerable interest in the possibility that eosinophils are important effector cells in FD and replication of these studies are waiting to be conducted in adults with FD. Corticosteroids have been the mainstay of pharmacological treatment for eosinophilic disorders, however, they have not been tested yet in FD.

Probiotics have been reported to be beneficial in the treatment of IBS and may act by improving mucosal permeability and altering the intestinal microbiota. ${ }^{92}$ Probiotics might improve $H$. pyloriassociated dyspepsia through an inhibitory effect on $H$. pylori, ${ }^{93}$ however, the effects of probiotics on $H$. pylori-negative FD is unclear. Igarashi et $\mathrm{al}^{82}$ reported that the overall bacterial community structure in the gastric fluid of patients with FD was significantly different from that in healthy controls, and the shifted composition of the gastric fluid microbiota was "restored" by treatment with Lactobacillus gasseri OLL271. ${ }^{82}$ A randomized controlled trial with L. gasseri OLL2716 in 116 patients with $H$. pylori-uninfected FD revealed that the symptom resolution was achieved by $17 \%$ and $35.5 \%$ in the placebo and L. gasseri OLL2716 $(P=0.048)$ arms, respectively. $^{94}$

Emerging data which account for the effectiveness of rifaximin in FD was reported. ${ }^{95}$ Adequate relief of global dyspeptic symptoms was $79 \%$ versus $47 \%$ in rifaximin and placebo, respectively, at 8 weeks $(P=0.008)$, as well as improvement in belching and postprandial fullness in sub-group analysis. Rifaximin might alter the intestinal gut microbiota, which has been demonstrated in IBS studies. ${ }^{96}$

Dietary factors are known to precipitate or exacerbate FD symptoms. Because of the association with NCG/WS, nutritional management may be beneficial. A gluten-free diet in patients with dysmotility-like dyspepsia symptoms and a normal endoscopy followed for 18 months resulted in dyspeptic symptom relief in $92 \%$ $(31 / 34) .{ }^{87}$ FODMAP can evoke the luminal distension which is 


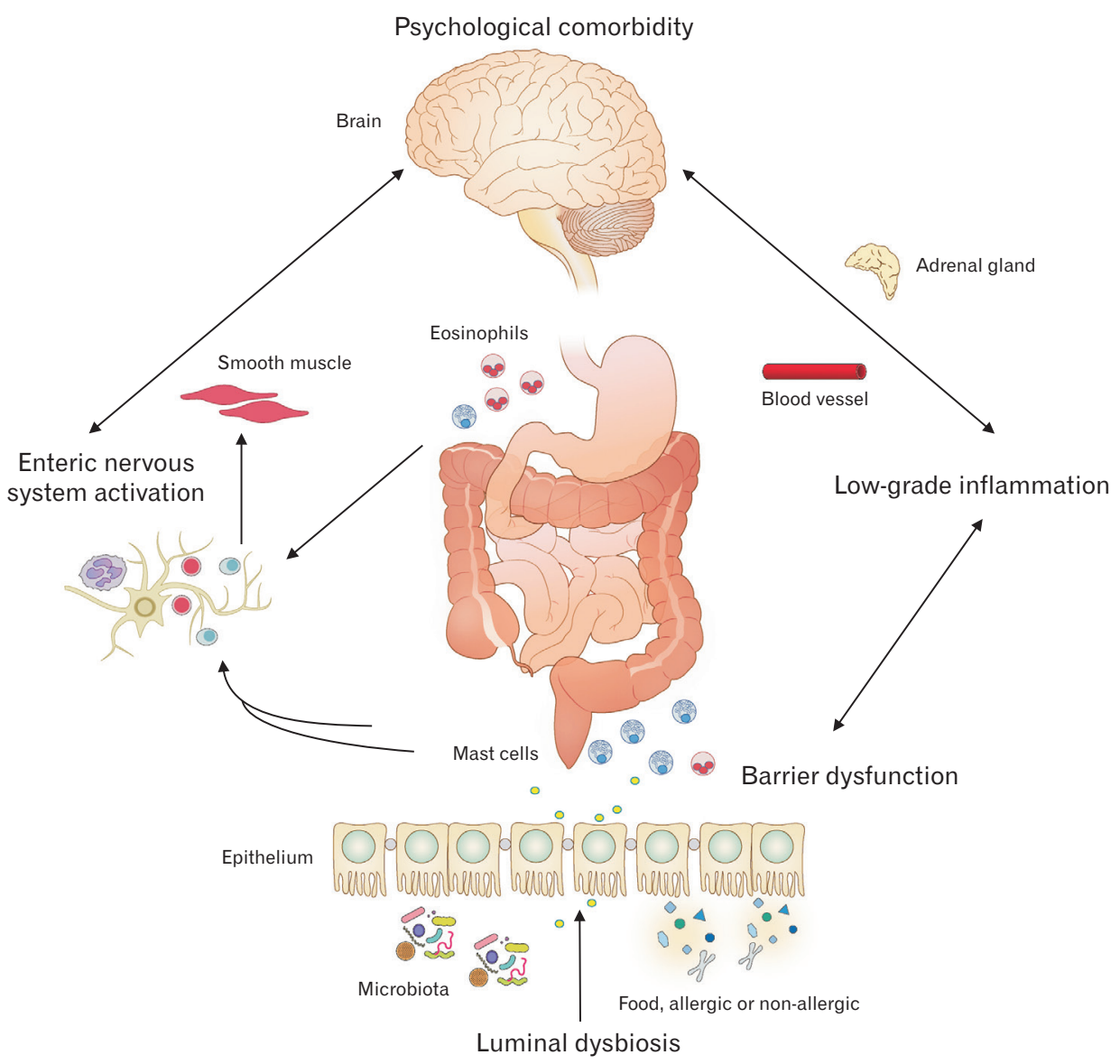

Figure 3. Low-grade duodenal inflammation in the etiopathogenesis of functional dyspepsia. related to symptom generation and associate with visceral hypersensitivity in IBS. ${ }^{97}$ There are several studies that show the efficacy of the low FODMAP diet in IBS. ${ }^{98}$ There is overlap of symptom manifestations between FD and IBS, and therefore, a low FODMAP diet might have some role in the management of FD, but has not been studied yet.

\section{Conclusions}

There are several lines of evidence that duodenal low-grade inflammation may be involved in the etiopathogenesis of FD inducing mucosal immune activation, duodenal barrier dysfunction, and sensory-motor dysfunction (Fig. 3). An altered duodenal gut microbiota, food antigens or infection may precipitate duodenal micro-inflammation in a subset of FD patients. If this hypothesis is correct, there are important implications in terms of potential new therapeutic targets in FD.
Financial support: None.

\section{Conflicts of interest: None.}

Author contributions: Hye-Kyung Jung drafted and revised the manuscript, and prepared figures; and Nicholas Talley designed and supervised the manuscript.

\section{References}

1. Stanghellini V, Chan FK, Hasler WL, et al. Gastroduodenal disorders. Gastroenterology 2016;150:1380-1392.

2. Tack J, Talley NJ, Camilleri M, et al. Functional gastroduodenal disorders. Gastroenterology 2006;130:1466-1479.

3. Stanghellini V, Ghidini C, Maccarini MR, Paparo GF, Corinaldesi R, Barbara L. Fasting and postprandial gastrointestinal motility in ulcer and non-ulcer dyspepsia. Gut 1992;33:184-190.

4. Thumshirn M, Camilleri M, Saslow SB, Williams DE, Burton DD, Hanson RB. Gastric accommodation in non-ulcer dyspepsia and the roles of Helicobacter pylori infection and vagal function. Gut 1999;44:5564.

5. Stanghellini V, Tosetti C, Paternico A, et al. Risk indicators of delayed 
gastric emptying of solids in patients with functional dyspepsia. Gastroenterology 1996;110:1036-1042.

6. Talley NJ, Verlinden M, Jones M. Can symptoms discriminate among those with delayed or normal gastric emptying in dysmotility-like dyspepsia? Am J Gastroenterol 2001;96:1422-1428.

7. Talley NJ, Locke GR 3rd, Lahr BD, et al. Functional dyspepsia, delayed gastric emptying, and impaired quality of life. Gut 2006;55:933-999.

8. Ronnestad I, Akiba Y, Kaji I, Kaunitz JD. Duodenal luminal nutrient sensing. Curr Opin Pharmacol 2014;19:67-75.

9. Lee KJ, Kim JH, Cho SW. Dyspeptic symptoms associated with hypersensitivity to gastric distension induced by duodenal acidification. J Gastroenterol Hepatol 2006;21:515-520.

10. Lee KJ, Tack J. Duodenal implications in the pathophysiology of functional dyspepsia. J Neurogastroenterol Motil 2010;16:251-257.

11. Talley NJ, Walker MM, Aro P, et al. Non-ulcer dyspepsia and duodenal eosinophilia: an adult endoscopic population-based case-control study. Clin Gastroenterol Hepatol 2007;5:1175-1183.

12. Walker MM, Talley NJ, Prabhakar M, et al. Duodenal mastocytosis, eosinophilia and intraepithelial lymphocytosis as possible disease markers in the irritable bowel syndrome and functional dyspepsia. Aliment Pharmacol Ther 2009;29:765-773.

13. Walker MM, Salehian SS, Murray CE, et al. Implications of eosinophilia in the normal duodenal biopsy - an association with allergy and functional dyspepsia. Aliment Pharmacol Ther 2010;31:1229-1236.

14. Du L, Chen B, Kim JJ, et al. Micro-inflammation in functional dyspepsia: a systematic review and meta-analysis. Neurogastroenterol Motil 2018;30:e13304.

15. Binesh F, Akhondei M, Pourmirafzali H, Rajabzadeh Y. Determination of relative frequency of eosinophils and mast cells in gastric and duodenal mucosal biopsies in adults with non-ulcer dyspepsia. J Coll Physicians Surg Pak 2013;23:326-329.

16. Hall W, Buckley M, Crotty P, O'morain CA. Gastric mucosal mast cells are increased in Helicobacter pylori-negative functional dyspepsia. Clin Gastroenterol Hepatol 2003;1:363-369.

17. Toukan AU, Kamal MF, Amr SS, Arnaout MA, Abu-Romiyeh AS. Gastroduodenal inflammation in patients with non-ulcer dyspepsia. A controlled endoscopic and morphometric study. Dig Dis Sci 1985;30:313-320.

18. Ashorn M, Ruuska T, Karikoski R, Välipakka J, Mäki M. Gastric mucosal cell densities in Helicobacter pylori-positive and -negative dyspeptic children and healthy controls. J Pediatr Gastroenterol Nutr 1994;18:146151.

19. Cheung CKY, Lan LL, Kyaw M, et al. Up-regulation of transient receptor potential vanilloid (TRPV) and down-regulation of brain-derived neurotrophic factor (BDNF) expression in patients with functional dyspepsia (FD). Neurogastroenterol Motil 2018;30:e13176.

20. Faure C, Patey N, Gauthier C, Brooks EM, Mawe GM. Serotonin signaling is altered in irritable bowel syndrome with diarrhea but not in functional dyspepsia in pediatric age patients. Gastroenterology 2010;139:249-258.

21. Lee EH, Yang HR, Lee HS. Analysis of gastric and duodenal eosinophils in children with abdominal pain related functional gastrointestinal disorders according to Rome III criteria. J Neurogastroenterol Motil 2016;22:459-469.

22. Wauters L, Nightingale S, Talley NJ, Sulaiman B, Walker MM. Functional dyspepsia is associated with duodenal eosinophilia in an Australian paediatric cohort. Aliment Pharmacol Ther 2017;45:1358-1364.

23. Vanheel H, Vicario M, Vanuytsel T, et al. Impaired duodenal mucosal integrity and low-grade inflammation in functional dyspepsia. Gut 2014;63:262-271.

24. Wauters L, Harris P, Serrano C, et al. PP-7 childhood recurrent abdominal pain is associated with duodenal eosinophilia regardless of $H$. pylori infection. J Pediatr Gastroenterol Nutr 2015;61:522-523.

25. Gargala G, Lecleire S, François A, et al. Duodenal intraepithelial T lymphocytes in patients with functional dyspepsia. World J Gastroenterol 2007;13:2333-2338.

26. Witte AB, Walker MM, Talley NJ, et al. Decreased number of duodenal endocrine cells with unaltered serotonin-containing cells in functional dyspepsia. Am J Gastroenterol 2016;111:1852-1853.

27. Weston AP, Biddle WL, Bhatia PS, Miner PB Jr. Terminal ileal mucosal mast cells in irritable bowel syndrome. Dig Dis Sci 1993;38:1590-1595.

28. Guilarte M, Santos J, de Torres I, et al. Diarrhoea-predominant IBS patients show mast cell activation and hyperplasia in the jejunum. Gut 2007;56:203-209.

29. Wouters MM, Vicario M, Santos J. The role of mast cells in functional GI disorders. Gut 2016;65:155-168.

30. Rothenberg ME. Eosinophilic gastrointestinal disorders (EGID). J Allergy Clin Immunol 2004;113:11-28.

31. Jacoby DB, Gleich GJ, Fryer AD. Human eosinophil major basic protein is an endogenous allosteric antagonist at the inhibitory muscarinic M2 receptor. J Clin Invest 1993;91:1314-1318.

32. Zhang X, Cheng E, Huo X, et al. Omeprazole blocks STAT6 binding to the eotaxin-3 promoter in eosinophilic esophagitis cells. PLoS One 2012;7:e50037.

33. Min JY, Ocampo CJ, Stevens WW, et al. Proton pump inhibitors decrease eotaxin-3/CCL26 expression in patients with chronic rhinosinusitis with nasal polyps: possible role of the nongastric H,K-ATPase. J Allergy Clin Immunol 2017;139:130-141, e11.

34. Pinto-Sanchez MI, Yuan Y, Hassan A, Bercik P, Moayyedi P. Proton pump inhibitors for functional dyspepsia. Cochrane Database Syst Rev 2017;11:CD011194.

35. Collins JS, Hamilton PW, Watt PC, Sloan JM, Love AH. Quantitative histological study of mucosal inflammatory cell densities in endoscopic duodenal biopsy specimens from dyspeptic patients using computer linked image analysis. Gut 1990;31:858-861.

36. Hooi JKY, Lai WY, Ng WK, et al. Global prevalence of Helicobacter pylori infection: systematic review and meta-analysis. Gastroenterology 2017;153:420-429.

37. Zhao B, Zhao J, Cheng WF, et al. Efficacy of Helicobacter pylori eradication therapy on functional dyspepsia: a meta-analysis of randomized controlled studies with 12-month follow-up. J Clin Gastroenterol 2014;48:241-247.

38. Lee SP, Lee SY, Kim JH, Sung HS, Park HS, Shim CS. Factors related to upper gastrointestinal symptom generation in 2275 Helicobacter pylori 
seroprevalent adults. Dig Dis Sci 2017;62:1561-1570.

39. Talley NJ, Ford AC. Functional dyspepsia. N Engl J Med 2015;373:1853-1863.

40. Futagami S, Itoh T, Sakamoto C. Systematic review with metaanalysis: post-infectious functional dyspepsia. Aliment Pharmacol Ther 2015;41:177-188.

41. Kindt S, Tertychnyy A, de Hertogh G, Geboes K, Tack J. Intestinal immune activation in presumed post-infectious functional dyspepsia. Neurogastroenterol Motil 2009;21:832-e56.

42. Futagami S, Shindo T, Kawagoe T, et al. Migration of eosinophils and CCR2-/CD68-double positive cells into the duodenal mucosa of patients with postinfectious functional dyspepsia. Am J Gastroenterol 2010;105:1835-1842.

43. Li X, Chen H, Lu H, et al. The study on the role of inflammatory cells and mediators in post-infectious functional dyspepsia. Scand J Gastroenterol 2010;45:573-581.

44. Collen MJ, Loebenberg MJ. Basal gastric acid secretion in nonulcer dyspepsia with or without duodenitis. Dig Dis Sci 1989;34:246-250.

45. Lu YX, Owyang C. Duodenal acid-induced gastric relaxation is mediated by multiple pathways. Am J Physiol 1999;276(6 Pt 1):G1501-G1506.

46. Danzer M, Jocic M, Samberger C, et al. Stomach-brain communication by vagal afferents in response to luminal acid backdiffusion, gastrin, and gastric acid secretion. Am J Physiol Gastrointest Liver Physiol 2004;286:G403-G411.

47. Samsom M, Verhagen MA, vanBerge Henegouwen GP, Smout AJ. Abnormal clearance of exogenous acid and increased acid sensitivity of the proximal duodenum in dyspeptic patients. Gastroenterology 1999;116:515-520.

48. Lee KJ, Demarchi B, Demedts I, Sifrim D, Raeymaekers P, Tack J. A pilot study on duodenal acid exposure and its relationship to symptoms in functional dyspepsia with prominent nausea. Am J Gastroenterol 2004;99:1765-1773.

49. Barbara G, Wang B, Stanghellini V, et al. Mast cell-dependent excitation of visceral-nociceptive sensory neurons in irritable bowel syndrome. Gastroenterology 2007;132:26-37.

50. Barbara G, Stanghellini V, De Giorgio R, et al. Activated mast cells in proximity to colonic nerves correlate with abdominal pain in irritable bowel syndrome. Gastroenterology 2004;126:693-702.

51. Schemann M, Camilleri M. Functions and imaging of mast cell and neural axis of the gut. Gastroenterology 2013;144:698-704, e4.

52. Schäppi MG, Borrelli O, Knafelz D, et al. Mast cell-nerve interactions in children with functional dyspepsia. J Pediatr Gastroenterol Nutr 2008;47:472-480.

53. Cirillo C, Bessissow T, Desmet AS, et al. Evidence for neuronal and structural changes in submucous ganglia of patients with functional dyspepsia. Am J Gastroenterol 2015;110:1205-1215.

54. Papadakis KA, Landers C, Prehn J, et al. CC chemokine receptor 9 expression defines a subset of peripheral blood lymphocytes with mucosal T cell phenotype and Th1 or T-regulatory 1 cytokine profile. J Immunol 2003;171:159-165.

55. Saruta M, Yu QT, Avanesyan A, Fleshner PR, Targan SR, Papadakis KA. Phenotype and effector function of CC chemokine receptor 9-ex- pressing lymphocytes in small intestinal Crohn's disease. J Immunol 2007;178:3293-3300.

56. Liebregts T, Adam B, Bredack C, et al. Small bowel homing T cells are associated with symptoms and delayed gastric emptying in functional dyspepsia. Am J Gastroenterol 2011;106:1089-98.

57. Jones MP, Tack J, Van Oudenhove L, et al. Mood and anxiety disorders precede development of functional gastrointestinal disorders in patients but not in the population. Clin Gastroenterol Hepatol 2017;15:10141020.e4.

58. Theoharides TC, Cochrane DE. Critical role of mast cells in inflammatory diseases and the effect of acute stress. J Neuroimmunol 2004;146:112.

59. Liu DR, Xu XJ, Yao SK. Increased intestinal mucosal leptin levels in patients with diarrhea-predominant irritable bowel syndrome. World J Gastroenterol 2018;24:46-57.

60. Schurman JV, Singh M, Singh V, Neilan N, Friesen CA. Symptoms and subtypes in pediatric functional dyspepsia: relation to mucosal inflammation and psychological functioning. J Pediatr Gastroenterol Nutr 2010;51:298-303.

61. O'Sullivan M, Clayton N, Breslin NP, et al. Increased mast cells in the irritable bowel syndrome. Neurogastroenterol Motil 2000;12:449-457.

62. Farthing MJ. Irritable bowel, irritable body, or irritable brain? Bmj 1995;310:171-175.

63. Fleisher DR. Cyclic vomiting syndrome: a paroxismal disorder of braingut interaction. J Pediatr Gastroenterol Nutr 1997;25(suppl 1):S13-S15.

64. Williams CL, Peterson JM, Villar RG, Burks TF. Corticotropinreleasing factor directly mediates colonic responses to stress. Am J Physiol 1987;253(4 Pt 1):G582-G586.

65. Martínez C, Vicario M, Ramos L, et al. The jejunum of diarrheapredominant irritable bowel syndrome shows molecular alterations in the tight junction signaling pathway that are associated with mucosal pathobiology and clinical manifestations. Am J Gastroenterol 2012;107:736-746.

66. Camilleri M, Gorman H. Intestinal permeability and irritable bowel syndrome. Neurogastroenterol Motil 2007;19:545-552.

67. Spiller RC, Jenkins D, Thornley JP, et al. Increased rectal mucosal enteroendocrine cells, $\mathrm{T}$ lymphocytes, and increased gut permeability following acute Campylobacter enteritis and in post-dysenteric irritable bowel syndrome. Gut 2000;47:804-811.

68. Marshall JK, Thabane M, Garg AX, et al. Intestinal permeability in patients with irritable bowel syndrome after a waterborne outbreak of acute gastroenteritis in Walkerton, Ontario. Aliment Pharmacol Ther 2004;20:1317-1322.

69. Villani AC, Lemire M, Thabane M, et al. Genetic risk factors for postinfectious irritable bowel syndrome following a waterborne outbreak of gastroenteritis. Gastroenterology 2010;138:1502-1513.

70. Farré R, Vicario M. Abnormal barrier function in gastrointestinal disorders. Handb Exp Pharmacol 2017;239:193-217.

71. Turner JR. Intestinal mucosal barrier function in health and disease. Nat Rev Immunol 2009;9:799-809.

72. Günzel D, Yu AS. Claudins and the modulation of tight junction permeability. Physiol Rev 2013;93:525-569.

73. Coëffier M, Gloro R, Boukhettala N, et al. Increased proteasome- 
mediated degradation of occludin in irritable bowel syndrome. Am J Gastroenterol 2010;105:1181-1188.

74. Piche T, Barbara G, Aubert P, et al. Impaired intestinal barrier integrity in the colon of patients with irritable bowel syndrome: involvement of soluble mediators. Gut 2009;58:196-201.

75. Campbell JM, Fahey GC Jr, Wolf BW. Selected indigestible oligosaccharides affect large bowel mass, cecal and fecal short-chain fatty acids, $\mathrm{pH}$ and microflora in rats. J Nutr 1997;127:130-136.

76. Charney AN, Micic L, Egnor RW. Nonionic diffusion of short-chain fatty acids across rat colon. Am J Physiol 1998;274(3 Pt 1):G518-G524.

77. Kerckhoffs AP, Samsom M, van der Rest ME, et al. Lower Bifidobacteria counts in both duodenal mucosa-associated and fecal microbiota in irritable bowel syndrome patients. World J Gastroenterol 2009;15:28872892.

78. Santos J, Saperas E, Nogueiras C, et al. Release of mast cell mediators into the jejunum by cold pain stress in humans. Gastroenterology 1998;114:640-468.

79. Moussaoui N, Jacobs JP, Larauche M, et al. Chronic early-life stress in rat pups alters basal corticosterone, intestinal permeability, and fecal microbiota at weaning: influence of sex. J Neurogastroenterol Motil 2017;23:135-143.

80. Imhann F, Bonder MJ, Vich Vila A, et al. Proton pump inhibitors affect the gut microbiome. Gut 2016;65:740-748.

81. Zhong L, Shanahan ER, Raj A, et al. Dyspepsia and the microbiome: time to focus on the small intestine. Gut 2017;66:1168-1169.

82. Igarashi M, Nakae H, Matsuoka T, et al. Alteration in the gastric microbiota and its restoration by probiotics in patients with functional dyspepsia. BMJ Open Gastroenterol 2017;4:e000144.

83. Feinle-Bisset $\mathrm{C}$, Horowitz M. Dietary factors in functional dyspepsia. Neurogastroenterol Motil 2006;18:608-618.

84. Duncanson KR, Talley NJ, Walker MM, Burrows TL. Food and functional dyspepsia: a systematic review. J Hum Nutr Diet 2018;31:390407.

85. Chua AS, Dinan TG, Rovati LC, Keeling PW. Cholecystokinin hyperresponsiveness in dysmotility-type nonulcer dyspepsia. Ann N Y Acad Sci 1994;713:298-299.

86. Elli L, Tomba C, Branchi F, et al. Evidence for the presence of non-celiac gluten sensitivity in patients with functional gastrointestinal symptoms: results from a multicenter randomized double-blind placebo-controlled gluten challenge. Nutrients 2016;8:84.

87. Santolaria S, Alcedo J, Cuartero B, et al. Spectrum of gluten-sensitive enteropathy in patients with dysmotility-like dyspepsia. Gastroenterol Hepatol 2013;36:11-20.

88. Potter M, Walker MM, Talley NJ. Non-coeliac gluten or wheat sensitivity: emerging disease or misdiagnosis? Med J Aust 2017;207:211-215.

89. Uhde M, Ajamian M, Caio G, et al. Intestinal cell damage and systemic immune activation in individuals reporting sensitivity to wheat in the absence of coeliac disease. Gut 2016;65:1930-1937.

90. Friesen CA, Kearns GL, Andre L, Neustrom M, Roberts CC, AbdelRahman SM. Clinical efficacy and pharmacokinetics of montelukast in dyspeptic children with duodenal eosinophilia. J Pediatr Gastroenterol Nutr 2004;38:343-351.

91. Friesen CA, Sandridge L, Andre L, Roberts CC, Abdel-Rahman SM. Mucosal eosinophilia and response to $\mathrm{H} 1 / \mathrm{H} 2$ antagonist and cromolyn therapy in pediatric dyspepsia. Clin Pediatr 2006;45:143-147.

92. Patel RM, Myers LS, Kurundkar AR, Maheshwari A, Nusrat A, Lin PW. Probiotic bacteria induce maturation of intestinal claudin 3 expression and barrier function. Am J Pathol 2012;180:626-635.

93. Takagi A, Yanagi H, Ozawa H, et al. Effects of Lactobacillus gasseri OLL2716 on Helicobacter pylori-associated dyspepsia: a multicenter randomized double-blind controlled trial. Gastroenterol Res Pract 2016;2016:7490452.

94. Ohtsu T, Takagi A, Uemura N, et al. The ameliorating effect of Lactobacillus gasseri OLL2716 on functional dyspepsia in Helicobacter pylori-uninfected individuals: a randomized controlled study. Digestion 2017;96:92-102.

95. Tan VP, Liu KS, Lam FY, Hung IF, Yuen MF, Leung WK. Randomised clinical trial: rifaximin versus placebo for the treatment of functional dyspepsia. Aliment Pharmacol Ther 2017;45:767-776.

96. Pimentel M, Lembo A, Chey WD, et al. Rifaximin therapy for patients with irritable bowel syndrome without constipation. N Engl J Med 2011;364:22-32.

97. De Giorgio R, Volta U, Gibson PR. Sensitivity to wheat, gluten and FODMAPs in IBS: facts or fiction? Gut 2016;65:169-178.

98. Gibson PR, Varney J, Malakar S, Muir JG. Food components and irritable bowel syndrome. Gastroenterology 2015;148:1158-1174, e4. 